\title{
APROXIMACIÓN A LA NATURALEZA DE DAESH EN TÚNEZ: DE EL BARDO A BEN GARDANE, UN AÑO DE TERROR.
}

\author{
Alberto Bueno ${ }^{1}$ \\ Universidad de Granada
}

\begin{abstract}
Resumen:
A partir del análisis descriptivo de los principales ataques perpetrados por Daesh en Túnez, este artículo estudia la naturaleza y evolución de la organización terrorista en el país magrebí. Así, examina las características y vicisitudes del ataque contra el Museo del Bardo en marzo de 2015, del atentado en la playa de Susa en junio de 2015, del atentado contra la Guardia Presidencial en noviembre de $2015 \mathrm{y}$, por último, de la ofensiva militar contra la localidad de Ben Gardane en marzo de 2016. Además, se detiene en algunos hechos anteriores a los mismos y que resultan relevantes para nuestro objeto de investigación, así como en la importante presencia de luchadores extranjeros tunecinos en Siria o Libia, y, de igual modo, en la amenaza que particularmente constituye Daesh Libia para el Estado tunecino.
\end{abstract}

Palabras clave: Túnez, Daesh, Terrorismo, Soldados del Califato en Túnez, Libia.

Titulo en Inglés: "The Approach to Daesh in Tunisia: From Bardo to Ben Gardane, aYear of Terror"

\begin{abstract}
:
Starting from a descriptive analysis of the main attacks by Daesh in Tunisia, this article examines the nature and evolution of the terrorist organization in this North African country. Thus, it examines the characteristics and vicissitudes of the attack on the Bardo Museum in March 2015, the attack on the Susa beach in June 2015, the bombing of the Presidential Guard in November 2015 and, finally, the military offensive against the town of Ben Gardane in March 2016. In addition, it presents some previous facts that are relevant in this research, such as the important presence of Tunisian foreign fighters in Syria or Libya, and, in particular, the threat of Daesh in Libya to the Tunisian State
\end{abstract}

Keywords: Tunisia, Daesh, Soldiers of the Caliphate in Tunisia, Libya.

Copyright (C) UNISCI, 2016.

Las opiniones expresadas en estos artículos son propias de sus autores, y no reflejan necesariamente la opinión de UNISCI. The views expressed in these articles are those of the authors, and do not necessarily reflect the views of UNISCI.

\footnotetext{
${ }^{1}$ Alberto Bueno es Coordinador del Observatorio de la Actividad Yihadista en el Magreb y el Sahel Occidental. Email: calbertobueno@gmail.com

DOI: http://dx.doi.org/10.5209/rev_RUNI.2016.n41.52676
} 


\section{Introducción}

El terrorismo de tipo yihadista constituye una de las principales amenazas para la transición política que vive Túnez. Aunque el fenómeno terrorista no era desconocido en el periodo prerrevolucionario, estos cinco años de cambio político se han visto convulsionados por cruentos ataques terroristas que han querido poner en jaque a los distintos gobiernos de transición y a la sociedad tunecina en general. Esta amenaza ha crecido cualitativa y cuantitativamente tras la violenta irrupción de la organización terrorista Daesh (el autodenominado Estado Islámico ${ }^{2}$ en el país. Dicho grupo ha perpetrado desde inicios de 2015 duros ataques dirigidos contra el aparato estatal político y de seguridad, el vital sector turístico y la integridad territorial misma del Estado magrebí, hechos que le han llevado a convertirse en el actor terrorista más preocupante de cuantos actúan en el país.

Este artículo analiza la configuración del Daesh en Túnez a partir de estos dramáticos atentados. Para ello, se repasan las circunstancias y características de los principales ataques terroristas ejecutados por el grupo, recogiendo el período comprendido entre marzo de 2015, cuando se produjo el atentado contra el Museo Nacional del Bardo, y marzo de 2016, mes en el que decenas de milicianos de la organización trataron de tomar militarmente un localidad fronteriza con Libia. Dicho estudio se completa atendiendo a otros elementos que influyen en la configuración del grupo en Túnez, como la presencia de foreign fighters tunecinos en otros escenarios de conflicto como Siria o Libia, donde hay una fuerte penetración e implantación de grupos yihadistas. En este último país, Daesh controla de facto casi 200 kilómetros de costa mediterránea y ha establecido en la ciudad de Sirte su capital y punto neurálgico. No han de soslayarse las graves consecuencias que estos factores pueden implicar para la seguridad tunecina como drivers de la capacidad terrorista de Daesh.

El análisis se desarrolla desde un enfoque de contingencia y basado en la información más actualizada disponible en fuentes abiertas. Por esta razón, se ha de advertir de la dificultad que muchas veces existe para contrastar de manera fehaciente los datos obtenidos. De ahí la complejidad de desarrollar tal estudio. No obstante, se considera necesario examinar la naturaleza y composición de Daesh en Túnez toda vez que se ha convertido en un actor criminal de primera magnitud preocupante para el país, para la seguridad regional y, por ende, también para la europea.

\section{De El Bardo a Ben Gardame: Daesh golpea a Túnez}

Los siguientes epígrafes están dedicados a responder al objetivo planteado en este artículo mediante el análisis de los atentados terroristas de Daesh en Túnez. Para ello se seguirá el iter criminal marcado por la organización mediante los que, se afirma, han sido los cuatro mayores golpes asestados por la organización: el ataque contra el Museo del Bardo (marzo de 2015), el atentado en la playa de Susa (junio de 2015), el atentado contra la Guardia Presidencial (noviembre de 2015) y la ofensiva militar contra la localidad de Ben Gardane (marzo de 2016).

Si bien, antes de adentrarse en este examen, conviene reparar en algunos antecedentes que pueden aportar claves sobre la conformación de Daesh en ese país. Se hace referencia, entre otros hechos, a los asesinatos de los líderes políticos Mohamed Brahmi y Chokri Belaid en 2013.

\footnotetext{
${ }^{2}$ En este documento se ha optado por usar de manera preferente el vocablo árabe Daesh (acrónimo de al-Dawla al-Islamiya al-Iraq al-Sham) para hablar de esta organización terrorista, dejando a un lado otras denominaciones como Estado Islámico (EI) o IS/ISIS (Islamic State/Islamic State of Iraq and the Levant, esto es, Estado Islámico de Iraq y el Levante).
} 


\subsection{Antecedentes. Conjeturas sobre los asesinatos de Chokri Belaid y Mohamed Brahmi}

En febrero de 2013, el político izquierdista Chokri Belaid era tiroteado a las puertas de su casa; en julio, era asesinado de once disparos Mohamed Brahmi, diputado tunecino por la ciudad de Sidi Bouzid (ciudad cuna de la "Revolución de los jazmines" tunecina) y antiguo líder del partido opositor de izquierdas Movimiento del Pueblo. Dos magnicidios que conmocionaron al país e hicieron tambalearse el gobierno del partido islamista Ennahda ${ }^{3}$. En un principio, las autoridades gubernamentales apuntaron como responsable de ambos magnicidios a la organización Ansar al-Sharia Túnez y señalaron en particular a Bubaker alHakim, más conocido por el sobrenombre de Abu Mokatal, como al menos uno de los ejecutores, quien en el momento de escribir estas líneas se encuentra en busca y captura. Esta inculpación tenía pleno lógica atendiendo a las características del terrorismo en Túnez en aquel momento, marcado por la fuerza de Ansar al-Sharia como organización dedicada a la promoción de salafismo yihadista más radical, sospechosa ciertamente de estar detrás de muchas de las acciones violentas dirigidas a dinamitar el proceso de cambio democrático. Así, el grupo extremista fue declarado como organización terrorista por el gobierno tunecino y otros potencias occidentales, como Estados Unidos o Reino Unido.

Sin embargo, esta supuesta certeza fue hecha añicos casi año y medio después, cuando unas horas de que terminara la campaña presidencial de diciembre de 2014, Daesh emitió un vídeo en el que el propio Abu Mokatal, junto con otros tres hombres armadas y arropados por la habitual parafernalia yihadista, reivindicó la autoría de los asesinatos de Brahmi y Belaid, al mismo tiempo que hacían explícito su juramente de lealtad a Abu Bakr al-Baghdadi ${ }^{5}$, emir de Daesh. Como ratificación de la autoría, varios meses después, a finales de marzo de 2015, en el número 8 de su revista propagandística "Dabiq", Mokatal reiteraba en una entrevista su responsabilidad por los crímenes de los dos líderes políticos de izquierdas.

Pese a esta confesión, es muy difícil asegurar que por aquel entonces Daesh ya dispusiera en 2013 de algún tipo de estructura estable en el país y que, por tanto, fuese el instigador directo de los dos magnicidios. Tal circunstancia es poco factible a pesar de los relatos propagandísticos. Ante estas dudas, sólo nos atrevemos a conjeturar aquí la teoría de

\footnotetext{
${ }^{3}$ Los magnicidios desencadenaron todo una oleada de protestas que provocaron una grave crisis política que acabó determinando la dimisión del entonces primer ministro, Hamadi Jebali, cuyo gobierno fue acusado, cuanto menos, de actuar con tibieza frente al islam más rigorista y radical.

${ }^{4}$ Ansar al-Sharia es un movimiento salafista de carácter yihadista fundado por Abu Iyadh, alias de Seif Allah Ibn Hussein. Esta organización está considerada como uno de los principales vectores de radicalización yihadista en el país especialmente durante los años revolucionarios, al igual que se le atribuyen buen parte de los ataques ejecutados contra fuerzas de seguridad en todo el país, en especial en torno a la región montañosa del Chaambi. $\mathrm{Su}$ proscripción, junto con la salida de mucho de sus militantes, bien al extranjero, bien para unirse a otras células yihadistas domésticas, ha menguado de forma considerable su fuerza e influencia en Túnez.

Para saber más acerca de los orígenes, actividad y evolución de Ansar al-Sharia Túnez, recomendamos los textos de Gartenstein-Ross, David: "Ansar al-Sharia Tunisia's Long Game: Dawa, Hisba and Jihad", International Centre for Counter-Terrorism, Research Paper (mayo 2013), en http://www.icct.nl/download/file/Gartenstein-Ross-Ansar-al-Sharia-Tunisia's-Long-Game-May-2013.pdf; Gartenstein-Ross, David, Soucy, Kathleen, y Moreng, Bridget: "Raising the Stakes: Ansar al-Sharia in Tunisia's Shift to Jihad", International Centre for Counter-Terrorism, Research Paper (febrero 2014), en http:/www.icct.nl/download/file/ICCT-Gartenstein-Ross-Moreng-Soucy-Raising-the-Stakes-ASTs-Shift-toJihad-Feb-2014.pdf; y Altuna, Sergio: “Hacia dónde se dirige el terrorismo yihadista en Túnez? La realidad del terrorismo yihadista en Túnez tras la ilegalización de Ansar al-Sharia", Instituto Español de Estudios Estratégicos, Documento de Opinión nº 27 (marzo 2015), en http://www.ieee.es/Galerias/fichero/docs opinion/2015/DIEEEO272015 TerrorismoYihadista Tunez SergioAltuna.pdf

${ }^{5}$ SITE Intelligence Group: "IS Video Urges Tunisians to Pledge to Group, Assassinate Political Leaders", 18 de diciembre de 2014, en https://news.siteintelgroup.com/Jihadist-News/is-video-urges-tunisians-to-pledge-togroup-assassinate-political-leaders.html
} 
que los atentados fueron posibles gracias a la acción particular de alguna célula en torno a Mokatal, muy probablemente militantes de Ansar al-Sharia, quienes de manera posterior habrían optado por cambiar su lealtad. Esta tesis puede apoyarse en otros casos como el de Ahmed al-Roussie, alias Abu Zakariya al-Tunisi, cerebro de los dos asesinatos, según aseguraron las autoridades tunecinos en su momento, y prohombre de Ansar al-Sharia a quien en el momento de su caída en combate se le asignaban funciones de comandante militar de una célula de Daesh en Sirte (Libia) ${ }^{6}$. De hecho es una constante que muchos de los combatientes tunecinos que integran las filas de Daesh u otros grupos yihadistas en Siria o Libia fueran miembros o simpatizantes de Ansar al-Sharia en el pasado, por lo que supone una teoría plausible acorde a los datos recabados.

En aquel primer vídeo, los terroristas también dejaban clara su odio contra la democracia en ciernes, abominando del proceso emprendido por la sociedad tunecina y coaccionándola con nuevas amenazas, en palabras de Abu Mosaab, otro de los terroristas que acompañaban a Abu Mokatal. En los meses siguientes hasta el atentado del Bardo, Daesh emitió igualmente numerosos llamamientos a sus militantes y simpatizantes para convertir a Túnez en "tierra de yihad"".

Otro de los antecedentes, y el cual es necesario conocer para establecer algunas coordenadas más del análisis, lo encontramos en ese mismo mes de diciembre de 2014, cuando se dio a conocer el grupo Jund al-Khilafah ("Soldados del Califato" en Túnez) jurando lealtad a Daesh y realizando un llamamiento para unirse a la yihad ${ }^{8}$. Sus amenazas contra el Estado tunecino y su proclamabas sobre el eventual inicio de una campaña de ataques no cesaron desde entonces 9 .

\subsection{El ataque contra el Museo del Bardo (marzo, 2015): "carta de presentación" de Daesh en Túnez}

Todas estas amenazas se materializaron el día 18 de marzo de 2015, cuando Túnez sufrió uno de los golpes terroristas más duros padecidos hasta ese momento. El ataque contra el Museo Nacional del Bardo comenzó a media mañana, momento en el que tres terroristas se internaron en el museo y abrieron fuego con fusiles de asalto tipo kalashnikov contra los turistas que allí se encontraban, después de un intercambio de disparos a las puertas del Parlamento (colindante con la instalación museística) ${ }^{10}$. Después de tres horas de tensión, las fuerzas de seguridad consiguieron abatir a dos de los terroristas, huyendo el tercero. La cifra

\footnotetext{
${ }^{6}$ Amara, Tarek: "Senior ISIS commander killed in Libya", Al Arabiya, 18 de marzo de 2015, en http://english.alarabiya.net/en/News/africa/2015/03/18/Senior-ISIS-commander-from-Tunisia-killed-inLibya.html

${ }^{7}$ SITE Intelligence Group: "Tunisia Attack Comes After Repeated Calls by IS for Violence in the Country", Insite Blog, 18 de marzo de 2015 en https:/news.siteintelgroup.com/blog/index.php/entry/372-tunisia-attackcomes-after-repeated-calls-by-is-for-violence-in-the-country; SITE Intelligence Group: "Tunisian Fighters Respond to IS Fighter Urging They Pledge Allegiance to IS", 18 de marzo de 2015, en http://ent.siteintelgroup.com/Statements/tunisian-fighters-respond-to-is-fighter-urging-they-pledge-allegiance-tois.html

${ }^{8}$ SITE Intelligence Group: "Alleged Group "Jund al-Khilafah in Tunisia" Pledges to IS", 8 de diciembre de 2014, en http://ent.siteintelgroup.com/Multimedia/alleged-group-jund-al-khilafah-in-tunisia-pledges-to-is.html

${ }^{9}$ SITE Intelligence Group: "Tunisian Fighters Respond to...", op.cit.

${ }^{10}$ Por esta razón se abrieron varias hipótesis acerca de las intenciones de los terroristas: primero se contempló la posibilidad de el objetivo prioritario de los atacantes fuera el Parlamento, donde a esa hora se debatía la importante reforma de la ley antiterrorista; al ser repelidos por las fuerzas de seguridad, los atacantes habrían tomado la resolución de adentrarse en el reciento del museo, contiguo a la cámara, convirtiéndolo así en un "objetivo de oportunidad". En segundo lugar, y ésta fue la hipótesis que cobró definitivamente mayor fuerza, se entendió que el museo era el objetivo primero y principal de los terroristas, siendo el parlamento sólo un objetivo tangencial dada su proximidad.
} 
final de víctimas fue de veintitrés: veintiún turistas (de los cuales, una pareja de nacionalidad española) y dos tunecinos, entre ellos un policía.

El ataque generó gran alarma ante la capacidad demostrada por los terroristas de golpear en pleno corazón de la capital, dirigiéndose contra un soft target que constituye un auténtico emblema ${ }^{11}$ de lo que es la principal industria del país: el turismo. Un modus operandi que hemos visto repetido en varias ocasiones en otras localizaciones (Francia, Estados Unidos) y que siguió los patrones de: sofisticación y planificación ${ }^{12}$, "objetivo blando" y gran repercusión mediática por su letalidad $\mathrm{y}$, de manera frecuente, su carácter simbólico, tal y como fue el caso.

Dicha alarma aumentó todavía más cuando los indicios que se iban obteniendo indicaban la autoría del grupo terrorista Daesh: al día siguiente, la plataforma yihadista de comunicación Ifriqiyah Media ${ }^{13}$ difundió un mensaje donde se aportaban los nombres de Jaber Khachnaui y Yassin Abidi como los autores de la masacre, felicitándose por los grandes resultados de una "operación sencilla"14. Ese mismo día, se emitió otro comunicado en el que Daesh asumía efectivamente la responsabilidad del ataque y prometía nuevos atentados. Hacía referencia a los mismos autores, aunque esta vez con sus alias de Abu Zakaria al-Tunisi y Abu Anas al-Tunisi, respectivamente ${ }^{15}$.

Gracias a estas informaciones se supo que tanto Anas como Zakaria habían estado en Libia (concretamente en Derna, cuando esta ciudad era el bastión de Daesh en el país ${ }^{16}$ ) en septiembre de 2014 para recibir entrenamiento, tras haber sido reclutados en mezquinas tunecinas. Igualmente, que Zakaria habría estado varios meses atrás en Irak o Siria las filas de Daesh. Posteriormente se conoció incluso que la seguridad tunecina había seguido y vigilado a Abu Anas, aunque pronto abandonaron su rastro al considerarse que no tenía vínculos con grupos armados ni era peligroso, en lo que a la postre resultó ser un fatal error de inteligencia.

En fechas posteriores a la masacre, Daesh publicó el ya citado número de "Dabiq" donde volvía a asumir la responsabilidad del ataque y alababa a sus ejecutores, quienes habían prestado su bay'ah (juramento de fidelidad) a Al-Baghdadi, según se afirmaba. El 31 de marzo, el grupo Soldados del Califato en Túnez difundió un audio el que se reafirmaba como

\footnotetext{
${ }^{11}$ No en vano se trata de uno de los complejos museísticos arqueológicos más importantes del Mediterráneo.

${ }^{12}$ Habeck, Mary: "The Tunisian Terrorist Attack: What Does It Mean?", Insite Blog, 25 de marzo de 2015, en https://news.siteintelgroup.com/blog/index.php/entry/374-the-tunisian-terrorist-attack-what-does-it-mean

${ }^{13}$ Este medio se ha sido ligado tradicionalmente a la katiba Oqba Ibn Nefaa (vid. epígrafe 2.2.1) y ha sido usado igualmente por grupos terroristas locales para la difusión de sus comunicados. Sin embargo, desde noviembre de 2014 había señales fehacientes de que esta plataforma podía servir de igual modo como altavoz de Daesh y sus células e individuos afines.

${ }^{14}$ SITE Intelligence Group: "Jihadi Media Group Promotes Bardo Museum Raid as "Simple Operation", Calls Muslims to Attack Tourists", 19 de marzo de 2015, en http://ent.siteintelgroup.com/Statements/jihadi-mediagroup-promotes-bardo-museum-raid-as-simple-operation-calls-muslims-to-attack-tourists.html

${ }^{15}$ SITE Intelligence Group: "IS Claims Bardo Museum Raid in Tunisian Capital, Threatens More Attacks", 19 de marzo de 2015, en http://ent.siteintelgroup.com/Statements/is-claims-bardo-museum-raid-in-tunisian-capitalthreatens-more-attacks.html

${ }^{16}$ Derna se convirtió en la primera gran ciudad bajo control de Daesh en octubre de 2014. Sin embargo, a partir de junio de 2015, el grupo empezó a perder la hegemonía en la población debido a las luchas entre facciones, seguida desde otoño por la presión de bombardeos de Estados Unidos que acabaron con la vida de su líder, Abu Nabil. Las últimas informaciones (marzo-abril de 2016) que se tienen es que Daesh habría perdido completamente sus posiciones a manos de tropas leales al gobierno. Sobre la toma de Derna a manos de Daesh, se puede leer el artículo de Zelin, Aaron Y.: "The Islamic State's First Colony in Libya", The Washington Institute, 10 de octubre de 2014, en http://www.washingtoninstitute.org/policy-analysis/view/the-islamic-states-first-colony-in-libya Sobre el asesinato de Abu Nabil, se puede consultar Baron, Kevin: "US Air Strike Hits ISIS in Libya, Chief Presumed Dead", Defense One, 14 de noviembre de 2015, en http://www.defenseone.com/threats/2015/11/breaking-us-airstrikes-hit-isis-libya-chief-presumed-dead/123702/
} 
parte de Daesh y asumía el ataque, además de amenazar con nuevos y más violentos atentados ${ }^{17}$. El ataque al Bardo fue expuesto como su macabra "carta de presentación", apuntando a continuación y de manera singularizada al presidente y al primer ministro tunecinos, a los responsables de Interior y Defensa, y a los miembros del ejército, la policía y la Guardia Nacional encargados de las operaciones antiterroristas, por "no ser creyentes" y patrocinar "la democracia y el secularismo" ${ }^{18}$. En su retórica del terror, se proclamaban ufanos ante la posibilidad de perpetrar ataques de mayor calibre atendiendo al impacto y las repercusiones de una ataque ejecutado con un puñado de muyahidín ${ }^{19}$.

Desentrañar la hipotética composición de este grupo se antoja una labor harto compleja pues la información disponible en fuentes abiertas y contrastadas a día de hoy no trasciende mucho más allá de los datos aportados. Si nos atenemos a los hechos descritos, la formación de este grupo se debería a la voluntad de tunecinos regresados de otras "tierras de yihad" como Libia y Siria por formar una célula a las órdenes del Daesh. Los hechos, si asumimos como verídicos los audios y la información divulgada por "Dabiq", de que tanto Abu Zakaria al-Tunisi como Abu Anas al-Tunisi hubieran pasado por campos de entrenamientos libios (si cabe, la visualización de las imágenes del asalto no deja lugar a dudas de que los atacantes contaban con experiencia militar) nos conduce necesariamente a esta teoría. Ello sin soslayar la posibilidad de que también pudieron contar con el apoyo de antiguos miembros de otros grupos yihadistas del país relacionados con AQMI o sin filiación determinada que hubieran cambiado su lealtad o hubieran dado el paso de conducirse a las órdenes de al-Baghdadi, o tunecinos "inspirados" que decidieron unirse a las filas de Daesh, esto es, se trataría aquí de un terrorismo homegrown ${ }^{20}$.

En último lugar y en relación con el atentado del Bardo, se ha de hacer referencia a un segundo grupo que igualmente sería fiel a Daesh: Talaiaa Jund al-Khilafah (Vanguardia de los Soldados del Califato). De su existencia sabemos gracias a un documento publicado por la Ifriqiyah Media, en el cual se señalaba que sus miembros habrían sido los responsables del atentado en el Bardo ${ }^{21}$. Esta información hay que acogerla con cautela debido a que, si bien el documento consignaba supuestamente a este grupo la autoría del ataque, tan sólo un día después de su publicación, "Dabiq" alababa expresamente a Soldados del Califato en Túnez por su proeza; una prueba indubitada que consolida la percepción de que es Daesh quien se encontraba detrás de dicho suceso, como hemos afirmado, pero que venía a contradecir la noticia de la Ifriqiyah Media.

Poca más información se dispone de la organización, pero sí, y esto es muy significativo, que habría sido el grupo designado por el Daesh para crear una wilayah del

\footnotetext{
${ }^{17}$ Carlino, Ludovico: "Emergence of new pro-Islamic State group indicates increased terrorism risk from Tunisian jihadists", IHS Jane's 360, 30 de marzo de 2015, en http://www.janes.com/article/50337/emergenceof-new-pro-islamic-state-group-indicates-increased-terrorism-risk-from-tunisian-jihadists

${ }^{18}$ SITE Intelligence Group: "Jund al-Khilafah in Tunisia" Declares Itself Part of IS, Claims Bardo Attack and Threatens More", 31 de marzo de 2015, en http://ent.siteintelgroup.com/Statements/site-intel-group-3-31-15-jktaudio-bardo-tunisia.html

${ }^{19}$ Gall, Carlotta: "Group Linked to Islamic State Claims Responsibility for Tunisia Attack", The New York Times, 31 de marzo de 2015, en http://nyti.ms/1yxw11j

${ }^{20}$ Una descripción más detallada acerca de la posible configuración del grupo Soldados del Califato en Túnez se puede encontrar en Bueno, Alberto: "Soldados del Califato en Túnez, ¿la afirmación de Daesh en el país magrebí", Grupo de Estudios en Seguridad Internacional, Análisis GESI no 10 (abril 2015), en http://www.seguridadinternacional.es/?q=es/content/soldados-del-califato-en-t $\% \mathrm{C} 3 \% \mathrm{BAnez}-\% \mathrm{C} 2 \% \mathrm{BFla}-$ afirmaci\%C3\%B3n-de-daesh-en-el-pa\%C3\%ADs-magreb $\% \mathrm{C} 3 \% \mathrm{AD}$

${ }^{21}$ Altuna, Sergio: "Ifriqiya Media just published this interesting document mapping jihadist groups and their affiliation", Twitter, 30 de marzo de 2015, en https://twitter.com/wellesbien/status/582544789645692929
} 
"califato" en Túnez, según algún autor ${ }^{22}$. Aún con su similar denominación a Jund alKhilafah, no hay indicios que sugieran una ligazón más estrecha entre ambas organizaciones. Otra de las posibilidades a considerar es que la Vanguardia, por el contrario, no fuera más que una estratagema mediática de aquéllos para agrandar su verdadera imagen e influencia.

2.2.1. Excurso sobre hipótesis alternativas acerca de la autoría del atentado: la katiba Oqua Ibn Nefaa

El atentado contra el Museo Nacional del Bardo presenta la peculiaridad, frente a los otros ataques terroristas narrados en este apartado, de que fue objeto de otra versión acerca de su autoría, lejos de la inculpación del Daesh. Una versión sostenida por las propias autoridades y que sólo la concurrencia de nuevos atentados, así como la cascada de comunicados reivindicativos se encargaron de desbaratar.

Las autoridades tunecinas apuntaron en un principio la responsabilidad de la katiba Oqba Ibn Nefaa (OIN, en adelante) ${ }^{23}$, grupo yihadista terrorista vinculado a Al Qaeda en el Magreb Islámico (AQMI, la organización regional de Al Qaeda), o incluso al-Sharia. Hasta el momento de los ataques era el grupo terrorista más activo en el país (vid. nota 22), consideración que llevó, junto con la publicación del primer mensaje reivindicativo por parte de la Ifriqiyah Media (vid. nota 12), a calibrar tal hipótesis. Algún audio en los días previos al ataque propiciaron el mantenerla: el día 17 se había difundido un mensaje de once minutos de duración en el que Wanas al-Faqih, un prominente miembro de Ansar al-Sharia Túnez y/o de la $\mathrm{OIN}^{24}$, animaba a la yihad en el país, relatando los ataques de la katiba en los últimos meses y amenazando con nuevas y más brutales embestidas, algunas de las cuales se producirían en breves, según afirmaba.

De hecho, en los días siguientes a la masacre, se precipitaron una serie de operaciones antiterroristas por parte de las autoridades tunecinas que culminaron con el arresto de más de medio centenar de sospechosos, en el marco de las cuales se consiguió abatir al líder de la OIN, Khaled Chaieb (alias Lokmar Abu Sakhr). Este incidente sirvió al Gobierno para insistir en la culpabilidad de la katiba (y, por ende, de AQMI), señalando la responsabilidad de Chaieb como cerebro de la operación. Sin embargo, los acontecimientos, como se señalaba,

\footnotetext{
${ }^{22}$ Habeck, Mary: "The Convergences of al-Qaeda and the Islamic State", Insite Blog, 17 de abril de 2015, en https://news.siteintelgroup.com/blog/index.php/entry/379-the-convergences-of-al-qaeda-and-the-islamic-state-1

${ }^{23}$ Esta katiba (voz naturalizada del árabe que se podría traducir como "batallón") se formó en 2012 por las unión de katibas más pequeñas presentes en la región de Kasserine, en el centro-oeste del país junto a la frontera argelina, caracterizada por su perfil montañoso en torno al monte Chaambi. En esta región, se fijó como misión el reclutamiento y entrenamiento de muyahidin para ser enviados a otros frentes, especialmente el libio, aunque pronto optó por pasar a la acción dentro de la propia Túnez. Se cree que su puesta en marcha estuvo auspiciada por militantes argelinos y tunecinos llegados desde el norte de Mali buscando refugio tras la puesta en marcha de la Operación "Serval" francesa y que estarían relacionados con AQMI. A su vez, existirían fuertes lazos entre la OIN y Ansar al-Sharia Túnez, toda vez que muchos militantes de ésta decidieran abandonar sus filas para unirse a aquélla, ya fuera por puro tacticismo ante el hostigamiento de las autoridades, ya por decisión estratégica de Ansar al-Sharia, la cual habría preferido mantener sus actividades de hisba (observancia de los principios islámicos) y dawa (predicación), para "externalizar" así su movimiento terrorista en la katiba. Este grupo terrorista es responsable de buena parte de los ataques y atentados contra las fuerzas de seguridad y del Ejército, sobre todo a partir del verano de 2013, entre ellos algunos de los más cruentos, como el asesinato de 16 militares en el verano de 2014; su última gran acción, aunque sin víctimas mortales, se produjo a finales del mes de marzo de 2016, cuando casi una veintena de milicianos tendieron una emboscada a miembros de la guardia nacional: éste es su modus operandi: emboscadas con armamento ligero y colocación de IED (Improvised Explosive Device, por sus siglas en inglés: artefacto explosivo improvisado) aprovechando la complicada orografía de la zona.

${ }^{24} \mathrm{Su}$ filiación permanece incierta; quizás lo fuera de ambas, en una transición, de Ansar al-Sharia a la OIN, realizada por más yihadistas tunecinos.
} 
acabaron por desmontar esta versión y ya no se duda en la responsabilidad del Daesh en la masacre del Bardo.

Es cierto que, el marco lógico de pensamiento (si atendemos al historial terrorista más reciente) podía invitar a sopesar más fácilmente esa posibilidad. Si bien, al final se vio que esto tenía más de negación de la preocupante realidad (que el Daesh se hacía presente dramáticamente en el país y había conseguido golpear duramente) que de consistencia fáctica.

\subsection{Atentado en Susa (junio, 2015): la industria turística, de nuevo en el punto de mira}

Después del atentado del Bardo, la campaña propagandística de Daesh fue in crescendo, lo que hacía temer un ataque de similares características. El ya mencionado número 8 de la revista propagandística "Dabiq" es el reflejo más claro de ello: su portada estaba ilustrada con el alminar de la Gran Mezquita de Kairuán, radicada en esa ciudad homónima del noreste de Túnez, uno de los templos más importantes del país y considerado el santuario musulmán más antiguo de Occidente, e impresa la proclama de que "únicamente la sharia [ley islámica] gobernará África", lo que sirve para ilustrar cómo Daesh había señalado definitivamente a Túnez en su estrategia de terror.

De igual modo, a principios del mes de abril de 2015 Daesh publicó un vídeo en el que llamaba a sus "hermanos" tunecinos a unirse a sus filas en Libia para, en un segundo paso, conquistar Túnez ${ }^{25}$. Nuevas noticias se tuvieron de Jund al-Khilafah en abril: el día 10 reivindicaron en un mensaje (no autentificado) una emboscada que había acabado tres días antes con la vida de cinco militares en Al-Meghila, en la región de Kasserine ${ }^{26}$; el 14, Ajnad al Khilafah, el que se erigiría como brazo mediático de la organización, publicó su primer vídeo en el cual se podían visualizar imágenes supuestamente del convoy del ejército asaltado en al-Meghila. En torno a la semana del 21 de abril, militantes de la organización trabaron combate con el ejército tunecino en torno al monte Sallum, con un saldo final de tres militares y diez yihadistas muertos ${ }^{27}$ : el modus operandi y la zona de enfrentamientos repetían los parámetros de la OIN, lo que alienta las conjeturaras acerca de que un grupo de disidentes de la katiba hubiera decidido alinearse con Daesh. A finales del mismo mes, por otra parte, Ajnad al-Khilafah publicó su primer documento en el cual animaba a perpetrar "operaciones de martirio", buena muestra de la voluntad del grupo por intensificar su grado de violencia.

Estos ejemplos brevemente enunciados mostraban la voluntad de la organización por volver a golpear. En efecto, el 26 de junio de 2015, un joven de apenas 24 años, Saif Rezgui, se dirigió a la playa del hotel Imperial Marhaba ataviado como un bañista más y allí sacó su arma tipo kalashnikov (de nuevo un fusil de asalto Ak-47 como medio) para abrir fuego contra los turistas que se encontraban en el complejo turístico. Posteriormente se dirigió al interior del mismo, donde descargó varias veces el fusil y lanzó varias granada. A continuación salió del recinto hasta que fue abatido por la policía. El número final de víctimas ascendió a 38, todas de ellas extranjeras. Un rasgo de la masacre fue, según relataron testigos,

\footnotetext{
${ }^{25}$ Zelin, Aaron Y.: "New video message from The Islamic State: "Message to Our Brothers in Tunisia - Wilāyat Ṭarābulus", Jihadology, 7 de abril de 2015, en http://jihadology.net/2015/04/07/new-video-message-from-theislamic-state-message-to-our-brothers-in-tunisia-wilayat-\%E1\%B9\%ADarabulus/; Shiloach, Gilad: "ISIS: First We Take Libya, Then We Take Tunisia", Vocativ, 8 de abril de 2015, en http://www.vocativ.com/world/isis2/isis-tunisia-libya-recruiting/

${ }^{26}$ Thomson, David: "Deux soldats tunisiens ont été tués mardi et trois autres blessés dans une embuscade dans la région de Kasserine", Twitter, 7 de abril de 2015, en https://twitter.com/ DavidThomson/status/586628993216077824; Al Huffington Post: "Cinq soldats tués et plusieurs autres blessés dans une embuscade à Sbeïtla", 7 de abril de 2015, en http://www.huffpostmaghreb.com/2015/04/07/tunisie-soldat-embuscade_n_7017178.html?utm_hp ref=maghreb ${ }^{27}$ Cemli, Aymen: "Dix terroristes abattus par l'armée à Jebel Selloum", Anadolu Agency, 24 de abril de 2015, en http://www.aa.com.tr/fr/politique/499167--tunisie-dix-terroristes-abattus-par-1-armee-a-jebel-selloum
} 
la intención declarada del terrorista por evitar la muerte de nacionales tunecinos, aún cuando tuvo la ocasión de asesinar a varios de $\operatorname{ellos}^{28}$, haciendo visible su propósito de dirigirse exclusivamente contra turistas extranjeros.

Horas después del ataque, Daesh reivindicó la autoría del mismo identificando al joven Rezgui como Abu Yahya al-Qayrawani ${ }^{29}$. Según se pudo saber posteriormente, Yahya habría viajado clandestinamente en enero a Libia para recibir entrenamiento durante un mes en las proximidades de Sabratha (una localidad situada a unos 45 kilómetros de la frontera con Túnez y a aproximadamente unos 60 kilómetros al oeste de Trípoli), en concreto en un antiguo cuartel militar de la población aledaña de al-Ajaylat ${ }^{30}$. Por este campo se estima que han pasado cientos de milicianos del grupo radical para entrenarse ${ }^{31}$ y donde habría coincidido con Abu Zakaria al-Tunisi y Abu Anas al-Tunisi, manteniendo el contacto con ellos hasta el momento del atentado contra el Museo del Bardo ${ }^{32}$. Según los conocidos de Rezgui, éste había mostrado signos de radicalización, aunque en ningún momento se esperaba que fuera capaz de algo así ${ }^{33}$ y ni tan siquiera la policía lo tenía en sus registros de potenciales sospechosos.

De nuevo un objetivo blando, ejecutado por un actor solitario: planificado pero sin la necesidad de contar con grandes recursos (un fusil de asalto y un puñado de granadas, fácilmente accesibles y asequibles debido al tráfico ilegal que se produce con Libia); y que buscaba dañar el principal sector económico del país, el turismo ${ }^{34}$, vital para la estabilidad de Túnez ${ }^{35}$, especialmente en un momento crítico y pleno de incertidumbres como el que vive.

El atentado de Susa fue un duro golpe para el turismo, ya gravemente resentido tras el ataque del Bardo. En 2015 el número de turistas en Túnez se redujo en un millón y los ingresos disminuyeron un $30 \%{ }^{36}$, lo que da idea del terrible efecto negativo que definitivamente los atentados del Bardo y Susa provocaron.

\footnotetext{
${ }^{28}$ Perejil, Francisco: "Me dijo: 'vete a casa, solo he venido a matar turistas", El País, 28 de junio de 2015, en http://internacional.elpais.com/internacional/2015/06/27/actualidad/1435392217 730014.html

${ }^{29}$ Joscelyn, Thomas: "Islamic State claims responsibility for massacre in Tunisia as death toll rises", The Long War Journal, 27 de junio de 2015, en http://www.longwarjournal.org/archives/2015/06/islamic-state-claimsresponsibility-for-massacre-in-tunisia-as-death-toll-rises.php

${ }^{30}$ Stephen, Chris: "Tunisia gunman trained in Libya at same time as Bardo museum attackers", The Guardian, 30 de junio de 2015, en http://www.theguardian.com/world/2015/jun/30/tunisia-beach-attack-seifeddine-rezguilibya-bardo-museum-attackers

${ }^{31}$ Bueno, Alberto: "Libia, una peligrosa sombra sobre Túnez", Grupo de Estudios en Seguridad Internacional, 14 de marzo de 2015, en

$\underline{\text { http://www.seguridadinternacional.es/blog.mosaico/?q=es/content/libia-una-peligrosa-sombra-sobre- }}$ $\mathrm{t} \% \mathrm{C} 3 \%$ BAnez

${ }^{32}$ Gall, Carlotta y Erlanger, Steven: "Gunman at Tunisian Beach Hotel Trained With Museum Attacker", The New York Times, 30 de junio de 2015, en http://www.nytimes.com/2015/07/01/world/africa/gunman-at-tunisianbeach-hotel-trained-with-museum-attackers.html?ref=africa

${ }^{33}$ Gall, Carlotta y Samti, Farah: "Tunisian Gunman Showed Subtle Signs of Radicalization", The New York

Times, 28 de junio de 2015, en http:/www.nytimes.com/2015/06/29/world/africa/tunisian-gunman-showedsubtle-signs-of-radicalization.html?ref=africa

${ }^{34}$ La turística población de Susa ya había sido objeto de un atentado suicida, afortunadamente sin víctimas, en 2013. Aquel fue el primero de estas características desde que en 2002 otro suicida asesinara a 21 personas en la isla de Djerba. Ambos atribuidos a Al-Qaeda.

${ }^{35}$ Johnson, Steve: "Tunisian economy fights off terror threat", Financial Times, 10 de julio de 2015, en http://www.ft.com/intl/cms/s/3/d694e892-26f7-11e5-9c4e-a775d2b173ca.html

${ }^{36}$ Deutsche Welle: "El terrorismo golpea la economía de Túnez", 8 de febrero de 2016, en http://www.dw.com/es/el-terrorismo-golpea-la-econom\%C3\%ADa-de-t\%C3\%BAnez/av-19034510
} 


\subsection{Atentado contra la guardia presidencial (noviembre, 2015): la seguridad del Estado en el punto de mira}

Desde entonces, las autoridades tunecinas situaron a Daesh como la prioridad número uno en su agenda antiterrorista, dejando de ser minimizada o infravalorada su existencia. Las numerosas operaciones contraterroristas que se realizaron desde ese momento atestiguaron, por un lado, los redoblados esfuerzos en este sentido y, por otro, cómo el elevado número de individuos relacionados con el Daesh es un problema serio en el país ${ }^{37}$.

Sin embargo, las medidas adoptadas, declaración de estado de emergencia incluido, no evitaron que el 24 de noviembre de 2015 Daesh volviera a atentar. Un joven suicida, Hosam Abdelli, hizo estallar su cinturón de explosivos frente a la puerta de un autobús que conducía a miembros de la Guardia Presidencial por la Avenida Mohamed V (una de las principales arterias de la capital tunecina), matando a doce de ellos.

El ataque fue reivindicado al día siguiente por Daesh, en un mensaje acompañado por una fotografía de Abdeblli con una chaleco de explosivos adosados al cuerpo y a quien nombraron como Abu Abdalá al-Tunisi ${ }^{38}$. Según algunas informaciones divulgadas, el joven de 26 años estaba fichado por la policía, sospechoso de ser un elemento radicalizado. Después del atentado, el gobierno tunecino cerró durante 15 días su frontera con Libia pues tenía la sospecha de que los materiales usados en el atentado habían sido introducidos ilegalmente desde este último territorio ${ }^{39}$.

\subsection{Asalto contra Ben Gardane (marzo, 2016): sorpresa estratégica}

En efecto, el atentado contra la Guardia Presidencial había sido la última constatación, una más, de la estrecha relación que todos los golpes terroristas de Daesh en Túnez guardan con Libia. Hombres, materiales o ambos elementos procedían o habían pasado por ese país.

Pero nunca antes como a comienzos de 2016 esta grave y preocupante realidad se mostró tan evidente, en lo que supuso un auténtico salto cualitativo y cuantitativo en la estrategia del terror de Daesh. Al amanecer del día 7, decenas de milicianos fuertemente armados cruzaron la frontera con Libia para tomar al asalto la ciudad de Ben Gardane, una localidad distante unos $30 \mathrm{~km}$. del límite entre ambos países y con una población de algo más de 50 mil habitantes.

Varios días antes ya se había producido una escena similar, aunque de mucha menor envergadura. Entonces un pequeño grupo de milicianos se infiltraron desde Libia a bordo de vehículos todoterreno y se enfrentaron en un tiroteo con fuerzas policiales, hasta que se atrincheraron en una casa en el Auya, una pequeña localidad aledaña a Ben Gardane, tomando como rehén a una familia. Las fuerzas de seguridad pusieron fin a la crisis asaltando el edificio y matando a cinco extremistas, identificados como miembros de Daesh. Hasta otros cinco individuos habrían conseguido huir.

No obstante, el asalto del día 7 se produjo a una escala mucho mayor. Los milicianos atacaron al unísono tres posiciones estratégicas, el cuartel general de la Guardia Nacional, una

\footnotetext{
${ }^{37}$ A este respecto se puede consultar la recopilación realizada en el "Observatorio sobre la actividad yihadista en el Magreb y el Sahel Occidental", del Grupo de Estudios en Seguridad Internacional http://www.seguridadinternacional.es/?q=es/content/observatorio-sobre-la-actividad-yihadista-en-el-magreb-yel-sahel-occidental

${ }^{38}$ SITE Intelligence Group: "IS claims suicide bombing on presidential guard bus in Tunisian capital", 25 de noviembre de 2015, en https://ent.siteintelgroup.com/Jihadist-News/is-claims-suicide-bombing-on-presidentialguard-bus-in-tunisian-capital.html

${ }^{39}$ González, Ricard: "El Estado Islámico asume la autoría del atentado suicida en Túnez", El País, 25 de noviembre de 2015, en http://internacional.elpais.com/internacional/2015/11/25/actualidad/1448447871_189436.html
} 
caserna de la policía y un cuartel del ejército, para posteriormente continuar la lucha en el corazón mismo de la ciudad, en un intento de tomar su control. Los duros enfrentamientos se prolongaron durante horas y tuvieron varios conatos más en los días siguientes, incluido el asalto a una vivienda donde se refugiaba Mohammed al-Kardi, uno de los planificadores del asalto y quien habría recibido entrenamiento en Siria y Libia, según las autoridades tunecinas. En los días posteriores prosiguieron las pesquisas con varias operaciones contraterroristas más que facilitaron decenas de detenciones y el descubrimiento de importantes arsenales. El número final de víctimas, según fuentes oficiales, fue de más de cuarenta milicianos y una docena de miembros de las fuerzas de seguridad muertos. No obstante, y según la televisión libia, algunos milicianos consiguieron escapar hacia Libia, pese al cierre de fronteras que el Gobierno había tunecino había decretado tras el primero de los ataques ${ }^{40}$.

Ben Gardane se convirtió en un auténtico escenario de guerra. En palabras del presidente Esssebsi, Daesh pretendió tomar el control de la ciudad y declararla como una "provincia del califato" ${ }^{41}$. Según algunos testimonios recogidos, varios de los asaltantes eran originarios de Ben Gardane y, por tanto, conocidos por los vecinos. La marca de Daesh en la ofensiva fue algo indubitado desde el primer momento, conforme a las declaraciones de testigos y del propio Gobierno tunecino, aunque hay que advertir que hasta el momento el grupo terrorista no ha emitido comunicado reivindicativo alguno. Junto a esos individuos autóctonos, también se tendría constancia del paso de varios de ellos por campos de entrenamiento en Sabratha y, por tanto, "su composición como células durmientes que [estaban] esperando en Ben Gardane" ${ }^{42}$ para actuar.

Se trató de un ataque perfectamente planificado y coordinado. El modus operandi se alejó de esas tácticas de guerrilla practicadas por la katiba OIN en las montañas occidentales o de las acciones suicidas en la ciudades. Por el contrario, se optó claramente por tácticas de insurgencia que en absoluto se dirigían contra soft targets, sino que arremetieron en primer lugar contra tres centros bien guarnecidos, buscando la confrontación directa con las fuerzas de seguridad tunecinas. Este asalto sin precedentes trató de tomar el control de una "posición estratégica" $^{43}$ en el camino entre Libia y Túnez, punto neurálgico de las comunicaciones y nodo de las redes de contrabando que cruzan con más o menos impunidad la frontera ${ }^{44}$. Sólo la inferioridad numérica de los asaltantes frente a una localidad fuertemente asegurada hizo que la intentona fracasara. Sin embargo, aunque fallido, el simbolismo de tan arrojada acción fue muy poderoso, pues recordó al puesto en práctica en otras ciudades que cayeron tristemente bajo el control de Daesh, como Mosul (en Irak) o Sirte (en Libia).

Acerca del porqué de la ofensiva, por un lado se encontraría la difundida por el Gobierno tunecino, el cual considera que

"el objetivo [de Daesh] era instigar una rebelión popular, provocar la deserción de las tropas del ejército e instaurar un emirato en la zona fronteriza con Libia [...]. Otra posible interpretación apunta que la acción [...] tenía unos objetivos más humildes, como hacerse con el control de instalaciones de la policía y el Ejército y hacer ondear allí su bandera. Según esta teoría, la milicia yihadista habría actuado con una cierta precipitación después del arresto dos días antes del hermano de uno de sus líderes en Ben

\footnotetext{
${ }^{40}$ Alamillos, Alicia: "Túnez, el próximo objetivo del califato sangriento de Daesh", ABC, 10 de marzo de 2016 , en http://www.abc.es/internacional/abci-tunez-proximo-objetivo-califato-sangriento-daesh201603101827 noticia.html

${ }^{41}$ RFI: "Tunisie: à Ben Guerdane, une attaque 'sans précédent' et 'coordonnée', 7 de marzo de 206, en http://www.rfi.fr/afrique/20160307-tunisie-attaque-ben-guerdane-libye-50-morts

${ }^{42}$ González, Ricard, op. cit.

${ }^{43}$ González, Ricard: "El confín que anhela el ISIS", El País, 3 de abril de 2016, en http://internacional.elpais.com/internacional/2016/03/18/actualidad/1458323888 888755.html

${ }^{44}$ Meneses, Rosa: "El botín del IS en Túnez", El Mundo, 10 de marzo de 2016, en http:/www.elmundo.es/internacional/2016/03/10/56e0212622601d097e8b4609.html
} 
Gardane. Ante la impresión de que las fuerzas de seguridad estaban estrechando su cerco y que las células podrían ser desarticuladas en cuestión de días, decidieron lanzar un ataque buscando una victoria de tipo más bien propagandístico que militar" ${ }^{45}$.

Otras fuentes señalan que la acción estaría espoleada por la presión militar contra posiciones de Daesh en Libia, en particular el ataque de Estados Unidos en febrero de este año contra campos de entrenamiento de la organización en Sabratha ${ }^{46}$. En efecto, el día 19 el ejército estadounidense bombardeó posiciones de Daesh en dicha localidad, uno de sus principales campos de entrenamiento y en el país, en cualquier caso el más cercano a Trípoli y al país tunecino, y por el que precisamente han pasado buena parte de los combatientes yihadistas tunecinos que habrían decidido unirse a la yihad ${ }^{47}$. Según el Pentágono, el objetivo de ese ataque aéreo era matar a Nourredine Chochuna, un líder yihadista procedente de Túnez acusado de ser el instigador de los atentados del Bardo y Susa, y quién además habría luchado con Daesh en Siria e Irak ${ }^{48}$. Aparte de Chochuna, en el ataque habrían muerto casi medio centenar de miembros de la organización.

\section{Foreign Fighters tunecinos y Daesh en Libia: Los otros componentes de la amenaza}

Del examen realizado de los principales atentados terroristas, se pueden extraer dos variables que parecen claras en la configuración de Daesh en Túnez: los foreign fighters, o combatientes tunecinos que han luchado o luchan en otros conflictos, y la amenaza directa que supone la dramática situación del "Estado fallido" libio y la presencia en éste de la organización terrorista. A ellas dedicaremos de manera breve las siguientes líneas.

En cuanto al primero de ellos, el importante número de muyahidín tunecinos salidos del país para luchar en diversos conflictos que entienden como causas de yihad, es una de las características más destacables de la amenaza terrorista tunecina, la cual supone un riesgo de seguridad interno de primer nivel. Efectivamente, Túnez es uno de los principales "exportadores" de combatientes hacia otros conflictos, como el libio o el sirio. Un hecho llamativo que preocupa mucho al Gobierno ${ }^{49}$ ante las cifras espectaculares de tunecinos que se habrían marchado del país con tales fines. Acogiendo con cautela las cifras facilitadas, se llegó a estimar a comienzos de 2015 en más de tres millares el número de combatientes extranjeros de origen tunecino, considerando los informes publicados tanto por el SITE Intelligence Group como por el International Centre for the Study of Radicalisation and

\footnotetext{
${ }^{45}$ González, Ricard: "Túnez, el próximo objetivo del ISIS", Alternativas, 18 de marzo de 2016, en http://blogs.elpais.com/alternativas/2016/03/el-isis-abre-un-nuevo-frente-en-t\%C3\%BAnez-.html ${ }^{46}$ Filiu, Jean-Pierre (2016): "Les défis pour la Tunisie et le monde du dijihadisme en Libye", Un si Proche Orient, 8 de marzo de 2016, en http://filiu.blog.lemonde.fr/2016/03/08/les-defis-pour-la-tunisie-et-le-monde-dujihadisme-en-libye/; Petré, Christine: "Daesh pushes at building base in southern Tunisia", 8 de marzo de 2016, en https://www.middleeastmonitor.com/3/169027/tunisia/daesh-pushes-at-building-base-in-southerntunisia\#gsc.tab $=0$

${ }^{47}$ El ataque fue seguido por una operación terrestre contra esas posiciones llevada a cabo por milicianos de "Amanecer Libio".

${ }^{48}$ EFE: "El Gobierno tunecino dice que los yihadistas de Libia planeaban atentar", en http://www.efe.com/efe/espana/portada/el-gobierno-tunecino-dice-que-los-yihadistas-llegados-de-libiaplaneaban-atentar/10010-2857589

${ }^{49}$ Reidy, Eric: "Tunisia cracks down on radicalization", Al-Monitor, 19 de mayo de 2015, en http://www.almonitor.com/pulse/originals/2015/05/tunisia-government-counter-extremism-anti-terroristbill.html?utm source=Al-Monitor+Newsletter+\%5BEnglish\%5D\&utm campaign=7c5a679161May 20 2015\&utm medium $=$ email\&utm term $=0$ 28264b27a0-7c5a679161-102467945
} 
Political Violence ${ }^{50}$. Otras fuentes elevan hasta 6.000 tan sólo el número de tunecinos que habrían viajado a $\operatorname{Siria}^{51}$ (a los que habría que añadir entonces los que se hubieran desplazado hasta la vecina Libia), pasando por los 5.500 anunciados por Naciones Unidas ${ }^{52}$. Además se ha de considerar que el Gobierno tunecino, y aquí siempre según sus fuentes, habría evitado la salida de entre unas 8.000 y 9.000 personas $^{53}$, volumen que ha llegado a elevarse hasta las $12.000^{54}$. La ciudad desde la cual habrían partido un mayor número de combatientes sería Ben Gardane $^{55}$, lo que puede ayudar a comprender las explicaciones dadas por el Gobierno tras el asalto de comienzos de marzo de 2016. Lo que parece fuera de toda duda es que Túnez posee en la actualidad el mayor número de combatientes por millón de ciudadanos y/o residentes, según las cifras ofrecidas en uno de los mejores trabajos que se han publicado sobre los foreign fighters en las filas de Daesh, editado por el Combating Terrorism Center de West Point ${ }^{56}$.

La preocupación, por tanto, estriba en el regreso de estos miles de tunecinos y cuáles pueden ser sus propósitos. De todos ellos se estiman que hayan regresado unos 700 , por lo que ahora el verdadero es monitorizarlos, algo que parece superar las capacidades de seguridad y de inteligencia del país ${ }^{57}$. Un análisis de las operaciones antiterroristas materializadas desde septiembre de $2014^{58}$ nos permite comprobar, a raíz de la desarticulación de células o la detención de individuos, las elevadas cifras de individuos que habrían regresado de Siria y Libia. El temor de las autoridades es que estos retornados se encuentren aún más radicalizados y cuenten con mejor entrenamiento, dispuestos a perpetrar acciones terroristas en el interior; circunstancias todas ellas de las que ya se pueden apreciar dramáticos ejemplos en los atentados detallados en los apartados anteriores. Igualmente resulta destacable la presencia de individuos o pequeñas células, con vínculos o al menos simpatías con Daesh, dedicadas principalmente a tareas de propaganda y proselitismo con el fin primordial de enviar combatientes a luchar a los países citados, aunque sin excluir, claro, la preparación y ejecución de atentados en el país.

Respecto a la segunda variable mencionada, ha quedado patente la grave amenaza que supone el conflicto libio para la seguridad tunecina, una terrible influencia con múltiples

\footnotetext{
${ }^{50}$ Neumann, Peter R.: "Foreign fighter total in Syria/Iraq now exceeds 20,000; surpasses Afghanistan conflict in the 1980s", International Centre for the Study of Radicalisation and Political Violence, 26 de enero de 2015, en http://icsr.info/2015/01/foreign-fighter-total-syriairaq-now-exceeds-20000-surpasses-afghanistan-conflict1980s/; SITE Intelligence Group: "Tunisia Attack Comes After Repeated Calls by IS for Violence in the Country", 18 de marzo de 2015, en https://news.siteintelgroup.com/blog/index.php/entry/372-tunisia-attack-comes-after-repeated-calls-by-is-forviolence-in-the-country

${ }^{51}$ The Soufan Group (2015): "Foreign Fighters. An updated Assessment of the Flow of Foreign Fighters into Syria and Iraq", diciembre de 2015, en http://soufangroup.com/wpcontent/uploads/2015/12/TSG ForeignFightersUpdate3.pdf

52 Al Arabiya: "Almost 5,500 Tunisians in militant ranks, U.N. experts say", 10 de julio de 2015, en http://english.alarabiya.net/en/News/middle-east/2015/07/10/Almost-5-500-Tunisians-in-jihadist-ranks-U-Nexperts-say-.html

${ }^{53}$ Cristiani, Dario: "The Geography of Discontent: Tunisia's Syrian Fighter Dilemma", Terrorism Monitor, vol. 12, no 20 (octubre 2014), pp. 7-9; Romdhani, Oussama: "North Africa: Beyond Jihadist Radicalization", World Affairs Journal, Enero-Febrero 2015.

54 Al Arabiya: "Tunisia blocks more than 12,000 would-be militants", 21 de mayo de 2015, en http:/english.alarabiya.net/en/News/africa/2015/04/18/Tunisia-blocks-more-than-12-000-would-bemilitants.html

${ }^{55}$ The Soufan Group, op. cit., p. 16.

${ }^{56}$ Dodwell, Brian, Milton, Daniel, y Rassler, Don (2016): "The Caliphate's Global Workforce: An Inside Look at the Islamic State's Foreign Fighter Paper Trail", Combating Terrorism Center at West Point.

${ }^{57}$ Souli, Sarah: "Tunisia: Why foreign fighters abandon ISIS", Al Jazeera, 3 de marzo de 2016, en http://www.aljazeera.com/news/2016/03/tunisia-foreign-fighters-abandon-isil-160301103627220.html

${ }^{58}$ Datos recogidos en el "Observatorio sobre la actividad yihadista..." op. cit.
} 
dimensiones: "entrenamiento, provisión de armas, fuentes de ingresos a través del contrabando, influencia ideológica, apoyo logístico y organizacional, así como su papel como país de tránsito para combatientes extranjeros" ${ }^{59}$. Como en la variable anterior, una consulta a las bases de datos disponibles ${ }^{60}$ revela el elevado número de detenidos en Túnez que habrían recibido entrenamiento o combatido en Libia, que habrían pasado por este país en su tránsito hacia Siria, o que tenían propósitos de hacerlo.

La frontera sur del país magrebí es limítrofe en casi 500 kilómetros con Libia, una terrible falla para la seguridad que el Gobierno tunecino trata de taponar de cualquier forma, incluso con la construcción de un muro fronterizo cuya efectividad cabe plantearse con escepticismo ${ }^{61}$. Libia se ha convertido en un "espacio generador de caos" dadas las cruentas fracturas internas que la cruzan y el epicentro del terrorismo en el norte del continente africano en el que se ha convertido ${ }^{62}$.

En este epicentro se sitúa Sirte, actualmente el bastión de la organización en el país. Si bien, el control de Daesh sobre el territorio se extiende a lo largo de 200 kilómetros de costa, amén de contar con posiciones en otras localizaciones, como la ya mencionada de Sabratha. Mediante el control de facto de territorio y localidades gracias a milicias leales o combatientes propios llegados de Siria e Irak ${ }^{63}$, opera bajo los postulados de luchar desde un enfoque local, llevar a cabo tareas de proselitismo e implantar el gobierno del "califato" ${ }^{64}$. Daesh anhela intensificar su presencia y acciones terroristas en Túnez para erigir una base que le posibilite establecer y declarar una nueva wilayah (denominada "wilayah Ifriqiya", un antiguo nombre medieval para denominar a la región de Túnez, noroeste de Libia y este de Argelia) ${ }^{65}$. Para ello estaría siguiendo igualmente una estrategia de "inspirar" a tunecinos para que se unan a sus filas, ante la ausencia de un grupo afín fuerte o territorio de facto bajo su control al que adherirse $^{66}$, dirección en la que se puede entender documentos publicados por militantes de la organización en los que urgen a Al-Baghdadi a llamar a la movilización para que los terroristas se unan a la yihad en Túnez ${ }^{67}$ o en el que un grupo de militantes yihadistas

\footnotetext{
${ }^{59}$ Kausch, Kristina (2015): "El problema libio de Túnez", FRIDE, Policy Brief No. 134 diciembre 2015, en http://fride.org/download/PB\%20esp\%20\%20134\%20ok\%20(2).pdf, p. 2.

60 "Observatorio sobre la actividad yihadista..." op. cit.

${ }^{61}$ Gaffey, Conor: "Can Tunisia's Border Barrier Stop Extremism Entering from Libya?", Newsweek, 9 de febrero de 2016, en http://europe.newsweek.com/can-tunisias-border-barrier-stop-extremism-entering-libya424531 ?rm=eu

${ }^{62}$ Duch, Emilio (2016): "Túnez y Libia: Expansión de las amenazas transfronterizas y sus posibles repercusiones en la seguridad de la región", Instituto Español de Estudios Estratégicos, Documento de Opinión 35/2016, 7 de abril de 2016, en

http://www.ieee.es/Galerias/fichero/docs_opinion/2016/DIEEEO352016 Tunez libia SeguridadRegion EDuchRamos.pdf

${ }^{63}$ Llamativas y preocupantes resultan las informaciones provenientes de la inteligencia estadounidense que advierten de un masivo desplazamiento de milicianos desde estos países y el territorio bajo control de Daesh hacia Libia, entre ellos importantes cuadros medios y varios líderes. El aumento de la presión en Siria e Iraq por las ofensivas lanzadas por el gobierno de Bashar al-Assad y Rusia, por un lado, y el gobierno iraquí y la coalición internacional liderada por EEUU, por otro, habría motivado esta huida, también con la intención de reforzar las posiciones en Libia.

${ }^{64}$ Zelin, Aaron Y.: "The Islamic State's model", The Washington Post, 28 de enero de 2015 http:/www.washingtonpost.com/blogs/monkey-cage/wp/2015/01/28/the-islamic-states-model/

${ }^{65}$ Zelin, Aaron Y. y David, Sena: "Between The Islamic State and al-Qaeda in Tunisia", ICSR, 11 de mayo de 2015, en http://icsr.info/2015/05/icsr-insight-islamic-state-al-qaeda-tunisia/

${ }^{66}$ Yousef, Nancy A.: "ISIS Pushes West, Eyeing a New Caliphate in Tunisia", The Daily Beast, 28 de abril de 2015, en http://www.thedailybeast.com/articles/2015/04/28/isis-pushes-west-eyeing-a-new-caliphate-intunisia.html

${ }^{67}$ SITE Intelligence Group: "Tunisian Jihadist Urges IS Leader Abu Bakr al-Baghdadi in Audio to Call for Mobilization to Tunisia", 15 de mayo de 2015, en https://news.siteintelgroup.com/Jihadist-News/tunisianjihadist-urges-is-leader-abu-bakr-al-baghdadi-in-audio-to-call-for-mobilization-to-tunisia.html
} 
tunecinos que proclaman su bay'ah al Estado Islámico (sin que se pudiera saber más información acerca de quién o quiénes formarían parte de este grupo) ${ }^{68}$.

\section{Daesh y Al-Qaeda: :Convergencia estratégica en el escenario tunecino?}

Este último apartado tiene un enfoque pretendidamente provocador que pretende romper algunos de los esquemas fijos a la hora de analizar la configuración del terrorismo yihadista internacional, en este caso particularizado en Túnez. Por ello, se recoge aquí la hipótesis planteada varios meses atrás por la investigadora Mary Habeck acerca de la naturaleza de los grupos terroristas que operan en el Estado magrebí y la pugna entre Al-Qeda y Daesh.

El crecimiento a todos los niveles de Daesh no sólo ha significado poner en jaque la seguridad global, sino que ha provocado un auténtico terremoto en la esfera yihadista internacional, donde ha entrado en una rivalidad mortal con Al-Qaeda ${ }^{69}$. Aunque ambas organizaciones puedan compartir objetivos finales, lo cierto es que difieren en "enemigos, estrategias, tácticas y otras preocupaciones/intereses fundamentales" ${ }^{70}$. Esta concurrencia también ha alcanzado África. Hace mucho que el ISIS situó el norte del continente africano como área de crecimiento de su pretendido "califato", un área de tradicional presencia de AlQaeda a través de AQMI y otros grupos que alineados con ella. Desde Libia aspira a ampliar sus "fronteras", mediante células propias y, sobre todo, grupos que juran lealtad a su líder espiritual: Soldados del Califato en Argelia, una escisión de AQMI ${ }^{71}$, en septiembre de 2014; la brigada Ansar Bayt al-Maqdis en el Sinaí egipcio, en noviembre del mismo año; o, más recientemente, en marzo de 2015, Boko Haram en Nigeria ${ }^{72}$; buenos ejemplos de cómo el Daesh consiguió granjearse una imagen de "fuerza arrolladora llamada a triunfar" entre sus adeptos $^{73}$. Ello no es obstáculo para que fuera de las zonas de conflicto emplee un modus operandi valiéndose también de individuos o células durmientes ${ }^{74}$. Hasta tal punto llega la fratricida lucha que se ha llegado a reseñar la orden que Al-Qaeda habría dado a sus militantes en la zona de "eliminar" (sic) a cualquiera que intentara introducir las ideas de Daesh ${ }^{75}$, un

\footnotetext{
${ }^{68}$ SITE, Intelligence Group: "IS Releases Pledge to Abu Bakr al-Baghdadi from Fighters in Tunisia", 18 de mayo de 2015, en https://news.siteintelgroup.com/Jihadist-News/is-releases-pledge-to-abu-bakr-al-baghdadifrom-fighters-in-tunisia.html

${ }^{69}$ Byman, Daniel y Williams, Jennifer: "ISIS vs. Al Qaeda: Jihadism's Global Civil War", The National Interest, 24 de febrero de 2015, en http://nationalinterest.org/feature/isis-vs-al-qaeda-jihadism\%E2\%80\%99s-global-civilwar-12304; Berger, J.M.: "The Islamic State vs. al Qaeda. Who's winning the war to become the jihadi superpower?", Foreign Policy, 2 de septiembre de 2014, en http://foreignpolicy.com/2014/09/02/the-islamicstate-vs-al-qaeda/

${ }^{70}$ Byman, Daniel L.: "Comparing Al Qaeda and ISIS: Different goals, different targets", Brookings Institution, 29 de abril de 2015, en http://www.brookings.edu/research/testimony/2015/04/29-terrorism-in-africa-byman

${ }^{71}$ Guri Abdelmalek, aka Jaled Abu Suleimán, era el líder de este grupo, quien fuera un antiguo hombre fuerte de AQMI en la región, pues había conseguido incluso ser la mano derecha de Abdelmalek Droukdel, jefe militar de AQMI y jefe, por tanto, de Al-Qaeda en el norte de África.

72 A estas organizaciones se le podría añadir Ansar Dine, un grupo islamista tuareg localizado en el norte de Mali relacionado en principio con AQMI, el cual, según el ministro del Interior de dicho país, se habría unido a Daesh. Jordán, Javier: "Ansar al-Sharia y la inquietante evolución del yihadismo en Libia", Instituto Español de Estudios Estratégicos, Documento de Opinión 145/2014, 16 de diciembre de 2014, p. 11, en http://www.ugr.es/ jjordan/yihadismo-Libia.pdf

73 Torres, Manuel R.: "El Estado Islámico mueve ficha en África", Grupo de Estudios en Seguridad Internacional, 9 de marzo de 2015, en

http://www.seguridadinternacional.es/blog.mosaico/?q=es/content/el-estado-isl\%C3\%A1mico-mueve-ficha-en$\% \mathrm{C} 3 \%$ A 1 frica

74 Jiménez, Laura: "Y el Estado Islámico llegó a Libia", Esglobal, 19 de febrero de 2015, en http://www.esglobal.org/y-el-estado-islamico-llego-a-libia/

${ }^{75}$ Kedar, Mordechai: "ISIS Will Try for Tunisia Next", Arutz Sheva, 6 de octubre de 2014, en http://www.israelnationalnews.com/Articles/Article.aspx/15761
} 
extremismo que se repite en otras zonas de conflicto como Siria, también en sentido inverso, con atentados de éste último grupo contra líderes opositores incluidos los dirigentes de AlQaeda $^{76}$.

Si bien, el escenario regional se halla en cierto modo repartido: Daesh se ubica principalmente en Libia y cuenta con grupos afines en Argelia y Nigeria; AQMI, por su parte, se encuentra sobre todo en Mali y el sur de Argelia, con capacidad para atentar aún más al sur, como en Burkina Faso o Costa de Marfil, como los atentados de los últimos meses han puesto en evidencia, en lo que pareciera una recuperación de la capacidad operativa de la organización, sin duda también reforzada por la reincorporación a sus filas del grupo AlMourabitoun. Sin embargo, el escenario tunecino está dividido, pues concurren elementos terroristas relacionados con Daesh con otros vinculados a un terrorismo homegrown de matriz doméstica nacido al albur de Ansar al-Sharia, así como con la ya mencionada katiba Oqba Ibn Nefaa. Posiblemente así tengamos unas de las situaciones más complejas en cuanto a multiplicidad de actores terroristas.

Estas coordenadas permiten acoger con mayor interés si cabe las ideas expuestas por la investigadora Mary Habeck, la cual formuló una hipótesis sumamente atractiva que vendría a romper de lleno con esa comprensión del mundo yihadista en clave de guerra civil entre Daesh y Al-Qaeda. Habeck planteaba en un controvertido texto, titulado The Convergences of al-Qaeda and the Islamic State ${ }^{77}$, el supuesto de que ese enfrentamiento entre ambas organizaciones no se estaría produciendo en Túnez, sino que, antes al contrario, concluía, Daesh y Al-Qaeda estarían cooperando o convergiendo a escala local. La hipótesis ya la había insinuado en un artículo previo a propósito del ataque contra el Museo del Bardo ${ }^{78}$. Las afirmaciones categóricas de las autoridades tunecinas de que los responsables eran miembros de Ansar al-Sharia las explicaba esta autora en base a tres hipótesis: primero, una simple falsa identificación de los autores en la confusión de las primeras horas tras el incidente; en segundo lugar, que ante unas identificaciones correctas en cuanto a los individuos, el error estribaría en considerar que los mismos todavía permanecían en sus grupos primigenios, es decir, la OIN o Ansar al-Sharia, y no haberse percatado de que se habría producido ya un cambio de lealtad a favor de ISIS (un supuesto ejemplificado en este trabajo); pero en tercer lugar, aunque sin desechar completamente esa segunda opción, planteó la tesis "revolucionaria": que atacantes de ambos grupos (AQMI y Daesh) hubieran colaborado en la ejecución del mismo, pactando así una conveniente tregua.

Esta última cuestión obligaría a revisar por completo el enfoque acogido hasta ahora con la finalidad de explorar y estudiar tanto estas acciones terroristas como la naturaleza misma de Daesh en territorio tunecino. Habeck apuesta por esa dicha convergencia en la escala local por varias razones:

a) Los diferentes grupos existentes, pese a sus distintas filiaciones no tendrían disputas o problemas entre ellos, lo que propiciaría la cooperación en acciones concretas.

b) Comparten enemigo(s).

c) Las células de Daesh habrían optado por priorizar sus agendas locales, colaborando allí donde fuera necesario con grupos de AQ, frente a las directrices de Al-Baghdadi contrarias a ello. Por su parte, Zawahiri no habría rehusado ni puesto impedimento alguno a que se produjera tal eventualidad.

\footnotetext{
${ }^{76}$ Stratfor: "Death Toll From Aleppo Car Bomb Reaches 32", 8 de abril de 2015, https://www.stratfor.com/sample/situation-report/syria-death-toll-aleppo-car-bomb-reaches-32

${ }^{77}$ Habeck, Mary: op.cit.

${ }^{78}$ Habeck, Mary: "The Tunisian Terrorist Attack: What Does It Mean?", Insite Blog, 25 de marzo de 2015, en https://news.siteintelgroup.com/blog/index.php/entry/374-the-tunisian-terrorist-attack-what-does-it-mean
} 
Habeck matizó enfatizando que "este fenómeno local no es necesariamente una señal de un cambio en las relaciones entre las organizaciones en su conjunto", las cuales mantendrían su lucha en otros escenarios. Aunque no circunscribe este fenómeno únicamente a Túnez, sí sostiene que las evidencias "localizadas" de confluencia están creciendo allí. Por tanto, siguiendo esta sugestiva idea, se ha de estimar la participación de ambas organizaciones en sucesos como el del Bardo, no como dicotómica, sino como concurrente, es decir, que componentes de atacantes de los dos grupos habrían participado en el ataque, a semejanza de lo sucedido en el atentado contra el semanario "Charlie Hebdo", la primera vez que miembros tanto de Al-Qaeda como de Daesh se coordinaron para perpetrar una acción terrorista ${ }^{79}$.

Bajo este prisma, se puede entender mejor movimientos como el de la Ifriqiyah Media, cuando en noviembre decidió atender a los comunicados de Daesh, pero sin deshacer los lazos con otras células o con la katiba Oqba Ibn Nefaa; o los mensajes que se publicaron en los días previos al atentado contra el museo, circunstancias señaladas en este trabajo e igualmente reseñadas por la autora. También permitiría interpretar en sus extremos adecuados las declaraciones de terroristas como Al-Binali ${ }^{80}$ o las de Abu Mokatal, donde en uno de sus audios reivindicativos animaba a sumarse a la lucha los grupos yihadistas en el Chaambi, región donde suele operar la OIN. Esta teoría enfatizaba la idea sugerida acerca de la existencia de algún tipo de vínculo entre individuos de ambas organizaciones, a propósito de los incidentes terroristas mencionados y de las vicisitudes, con respecto a los distintos individuos y/o grupos que intervinieron, que los acompañaron. Así, por ejemplo, tendría mayor sentido el alto número de militantes ligados a la katiba (empezando por su malogrado líder, Khaled Chaieb) que han sido detenidos por su presunta implicación en el ataque al museo.

Por tanto, y en conclusión, esta arriesgada hipótesis proporciona el marco adecuado para progresar en el rompecabezas, pensando no sólo en el trasvase de combatientes de un grupo a otro, bien como deserciones, bien como giro táctico (lo que en efecto se ha producido), sino también en el encuentro interesado y estratégico, con plenas consecuencias en el plano operacional, entre estos dos grupos. Es ésta, sin duda, una idea muy interesante a tener en cuenta tanto de forma retrospectiva, para el análisis de la irrupción y desarrollo del yihadismo en Túnez, como en trabajos futuros contemplándolo para otros escenarios. Ante la falta de mayores indicios y por el análisis de los acontecimientos realizado en los párrafos superiores, esta tesis se quedará por ahora aquí, en cualquier caso como recordatorio útil de la necesidad de confrontar ideas.

\section{Conclusiones}

Del análisis descriptivo realizado en este trabajo se pueden inducir algunos de los elementos definitorios de la configuración de Daesh en Túnez.

En primer lugar, y en cuanto a su naturaleza, hay un importante componente "doméstico", dado que el país ya contaba una importante militancia yihadista, donde desempeñó un papel fundamental Ansar al-Sharia. En segundo, mucha de esta militancia decidió salir al extranjero para combatir, encuadrándose con frecuencia en las filas de Daesh y de ahí que a su regreso cometan actos violentos en su nombre; a día de hoy Túnez es el país con mayor número de foreign fighters en Siria y Libia. En tercero, y en relación a esta última

\footnotetext{
${ }^{79}$ Ruiz, Rosa: "Coto al fanatismo", Revista Española de Defensa, no 314 (febrero 2015), pp. 6-11.

${ }^{80}$ Se tienen sospechas de que en una reunión acaecida entre finales de octubre y principios de noviembre de 2014 en Libia, Turki al-Binali, un ideólogo de la esfera de Daesh, habría animado a los líderes terroristas allí presentes a incrementar su ayuda a la OIN: Bueno, Alberto: "Libia, una peligrosa sombra..." op. cit.
} 
cuestión, Libia desempeña un papel fundamental en el ascenso de Daesh en Túnez, nutriendo de terroristas entrenados militarmente las células que posteriormente atentan en este país: que en dos de los atentados los terroristas hubieran pasado por campos libios, que en el tercero los materiales para cometer el acto suicida probablemente procedieran de ese mismo país y que la ofensiva de Ben Gardane se proyectara desde Libia no hacen sino confirmar tales extremos.

En cuanto al modus operandi, se observa que los atentados descritos respondían a una manera de proceder ya conocida: terroristas suicidas o, cuando menos, dispuestos al martirio, que atacan objetivo blandos buscando una alta letalidad y, sobre todo, un altísimo impacto mediático. La sencillez de los mismos, un hombre o un puñado de individuos con fusiles de asalto y granadas, no debe confundirse con una ausencia de planificación: son ataques que se revelan altamente eficaces por la dificultad de ser abortados previamente o de fracaso, así como la consecución de los objetivos señalados. El Bardo, Susa o el atentado contra la Guardia Presidencial responden a estas ideas.

No obstante, el ataque contra Ben Gardane ha supuesto todo un punto de inflexión en la ofensiva de Daesh contra Túnez. El asalto fue una auténtica sorpresa estratégica perfectamente coordinada y de consecuencias imprevisibles en caso de que los militantes del Daesh hubieran logrado sus propósitos. Militantes que, a su vez, se descubrieron capaces de llevar a cabo una operación más propia de un grupo insurgente que de una organización terrorista, lo que supone un verdadero salto cualitativo y cuantitativo en su escalada violenta. Hay que contemplar obligatoriamente la posibilidad de que ataques de similar entidad e igual o mayor calibra se repitan en el corto plazo. Estos hechos justifican el temor de las autoridades tunecinas a una intervención militar extranjera en Túnez. El conflicto libio amenaza con desbordar en cualquier momento las frágiles capacidades del pequeño estado magrebí.

En lo que respecta en concreto a Daesh, éste ha demostrado su determinación por extender su "califato" a Túnez. Los atentados analizados y las circunstancias que los rodearon amparan el afirmar tanto que Daesh cuente, en efecto, con algún tipo de estructura, como que pretende intensificar sus niveles de penetración y violencia en el país. Dicha estructura estaría compuesta por yihadistas retornados, individuos "inspirados" y combatientes tunecinos que habrían decidido mudar su filiación radical para nutrir las filas de Daesh en Túnez, probablemente muchas de ellas células durmientes que podrían incrementar rápidamente, por tanto, su actividad.

Son éstas circunstancias que sobrepasan con mucho las capacidades de Túnez y que hacen imprescindible una reforma del sector de seguridad del país ${ }^{81}$, así como el apoyo decidido de la comunidad internacional a nivel securitario y de inteligencia.

\footnotetext{
${ }^{81}$ International Crisis Group: 'Reform and Security Strategy in Tunisia', Middle East and North Africa Report 161. 23 de julio de 2016, en http://www.crisisgroup.org/en/regions/middle-east-north-africa/northafrica/tunisia/161-reform-and-security-strategy-in-tunisia.aspx
} 